\title{
Monitoring Coastal Marshes for Persistent Saltwater Intrusion
}

Maria Kalcic, ${ }^{1}$ Callie Hall, ${ }^{2}$ Jeff Russell, ${ }^{3}$ and Rose Fletcher ${ }^{1}$

1 Science Systems and Applications, Inc., John C. Stennis Space Center, MS 39529 USA ${ }^{2}$ NASA, Code PA30, John C. Stennis Space Center, MS 39529 USA ${ }^{3}$ NRL, Code 7440, John C. Stennis Space Center, MS 39529 USA
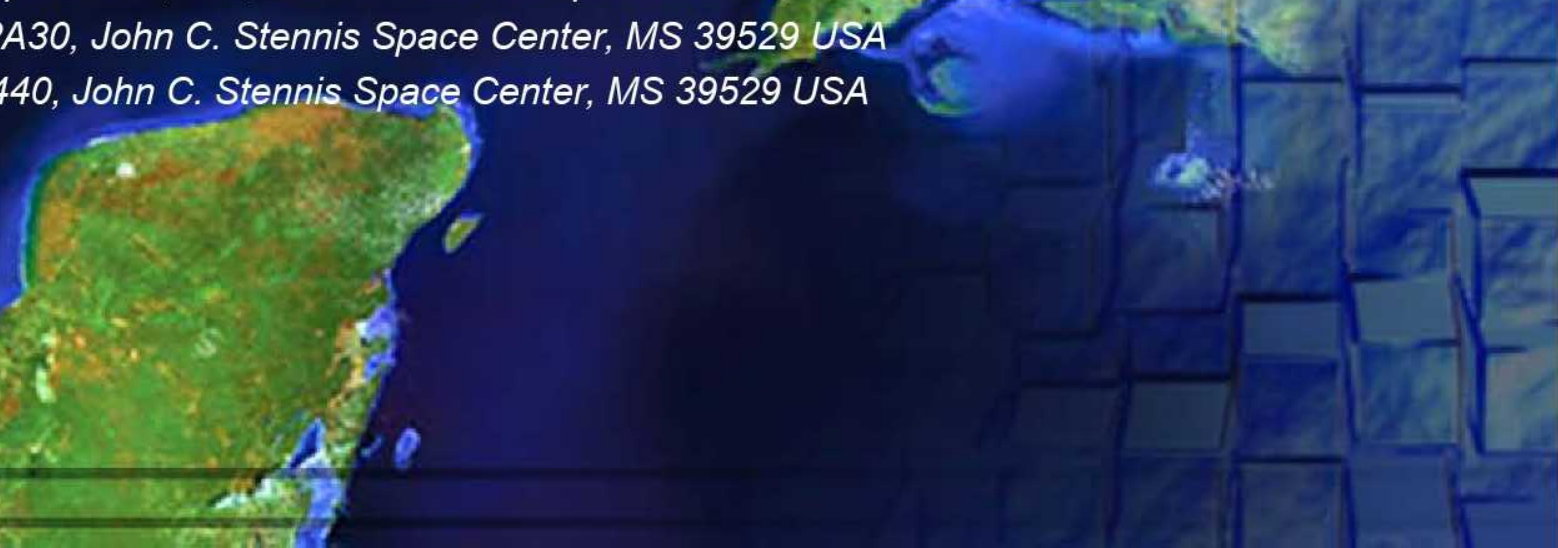


\section{Primary Goal}

- Provide resource managers with remote sensing products that support ecosystem forecasting models requiring salinity and inundation data.

- Work supports the habitat-switching modules in the Coastal Louisiana Ecosystem Assessment and Restoration (CLEAR) model, which provides scientific evaluation for restoration management (Visser et al., 2008). 


\section{Project Description}

- Daily MODIS time series are used to generate vegetation, water, and soil indices.

- Daily indices are used to compute percent flooding over any period of time and will be validated with a lidar Digital Elevation Model.

- Higher resolution data (e.g., Landsat) are used to compute salinity indirectly using CRMS ground truth and modeling.

- Percent inundation and salinity are merged to produce data for models like CLEAR Habitat Switching Model for coastal marshes.

\section{GOMA Relationship}

- Ecosystem Integration and Assessment

- EIA-2: Data gap analysis and acquisition in support of resource management

- EIA-3: Develop a Gulf of Mexico Ocean and Coastal Mapping and Monitoring Master Plan

- EIA-4: Implementation of the Coastal and Marine Ecological Classification Standard (CMECS) in the Gulf of Mexico

- Coastal Community Resilience

- Assess risks to natural environment

\section{Potential Partners/Collaborators}

- USGS National Wetlands Research Center-CRMS (Coastwide Reference Monitoring System)

- Barataria Terrebonne National Estuary Program

- Louisiana Dept. of Natural Resources (LDNR)

- NOAA Fisheries Service

\section{Related Proposals}

- Monitoring Coastal Marshes for Persistent Flooding and Salinity Stress (Radar emphasis) submitted 10/2008 under ROSES A:28 Gulf of Mexico by: Kalcic (SSAI); Hall (NASA); Steyer (USGS) 


\section{Habitat Switching Algorithm}
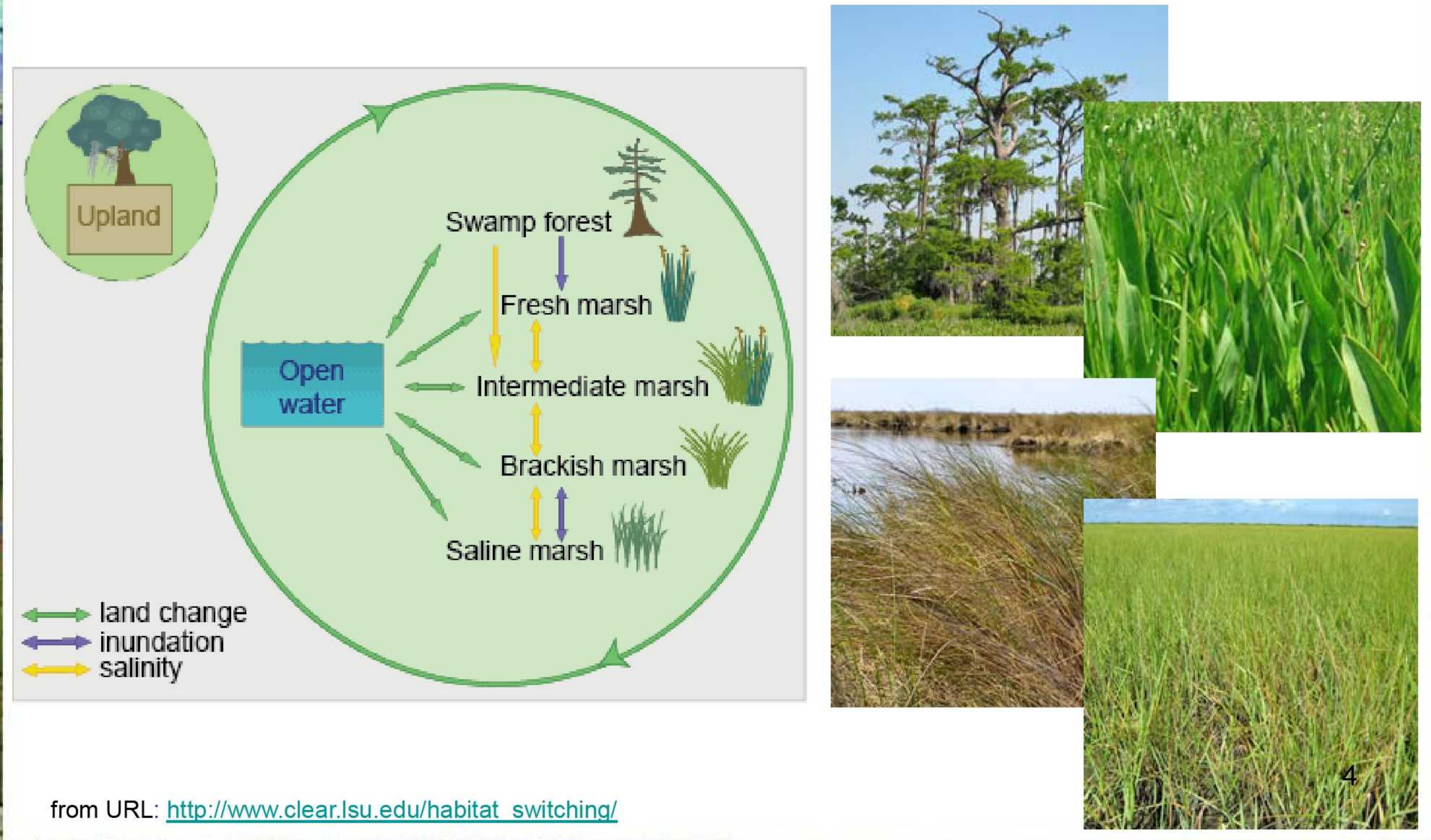


\section{Coastwide Reference Monitoring System (CRMS)}

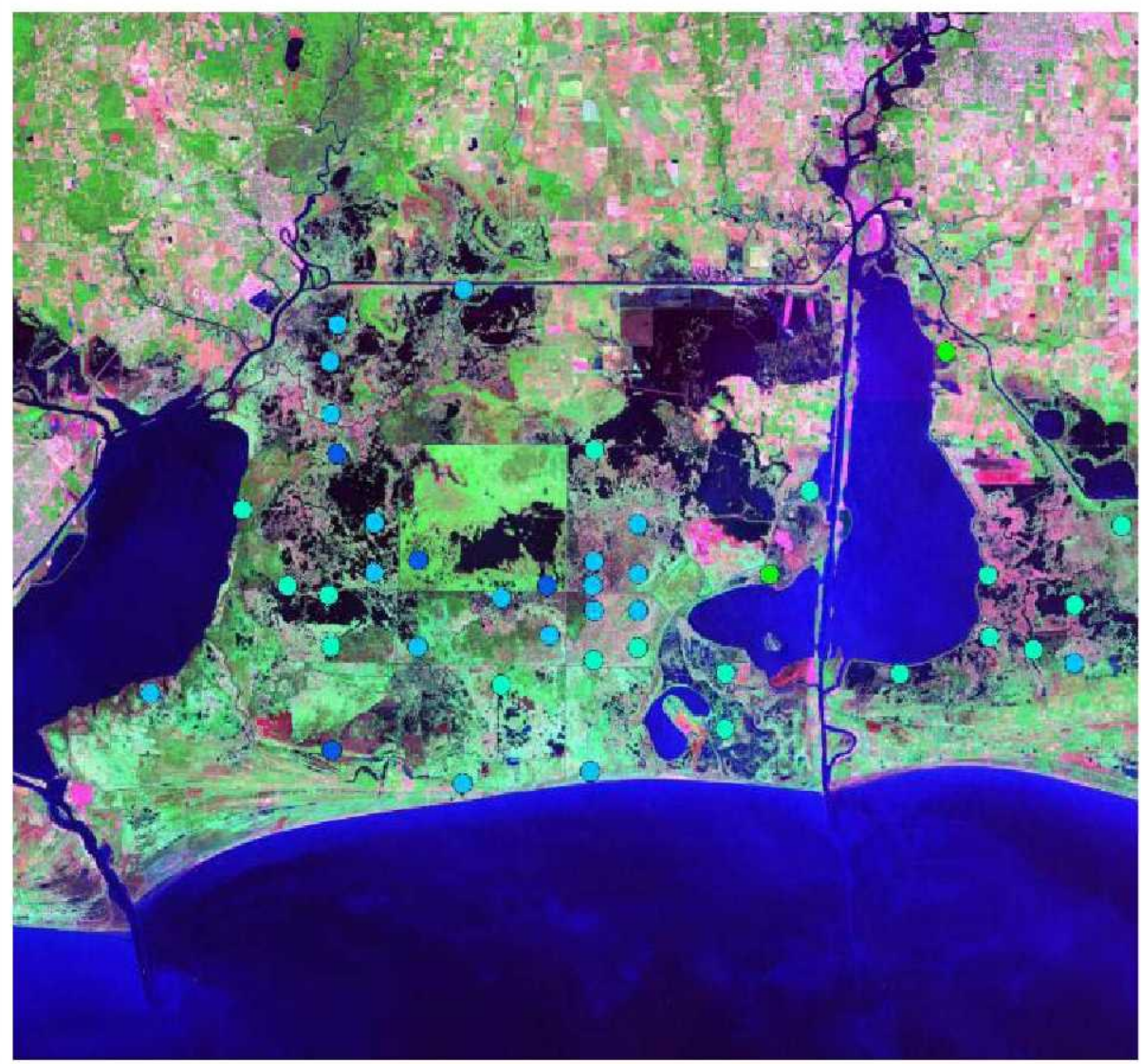

- 390 Stations across Coastal Louisiana Measurements include:

\section{- Hydrology}

water level, temperature, specific conductance, and salinity

- Accretion data

- Forested Swamp Vegetation Data

- Herbaceous Marsh Vegetation Data

- Soil Properties

wet $\&$ dry soil pH, soil-specific conductance, soil salinity, soil moisture content, bulk density, percent organic matter, and wet \& dry volume

- Surface Elevation

Data available at http://www.lacoast.gov/crms2/Home.aspx 


\section{NASA Time Series Product Tool}

- NASA SSC developed the Time Series Product Tool (TSPT) to derive daily normalized difference vegetation index (NDVI) values from the Moderate Resolution Imaging Spectroradiometer (MODIS) Aqua/Terra satellite data.

NDVI time series were developed daily for years 2000-2007.

In addition to NDVI, TSPT computes the normalized difference water and soil indices (NDWI and NDSI, respectively).

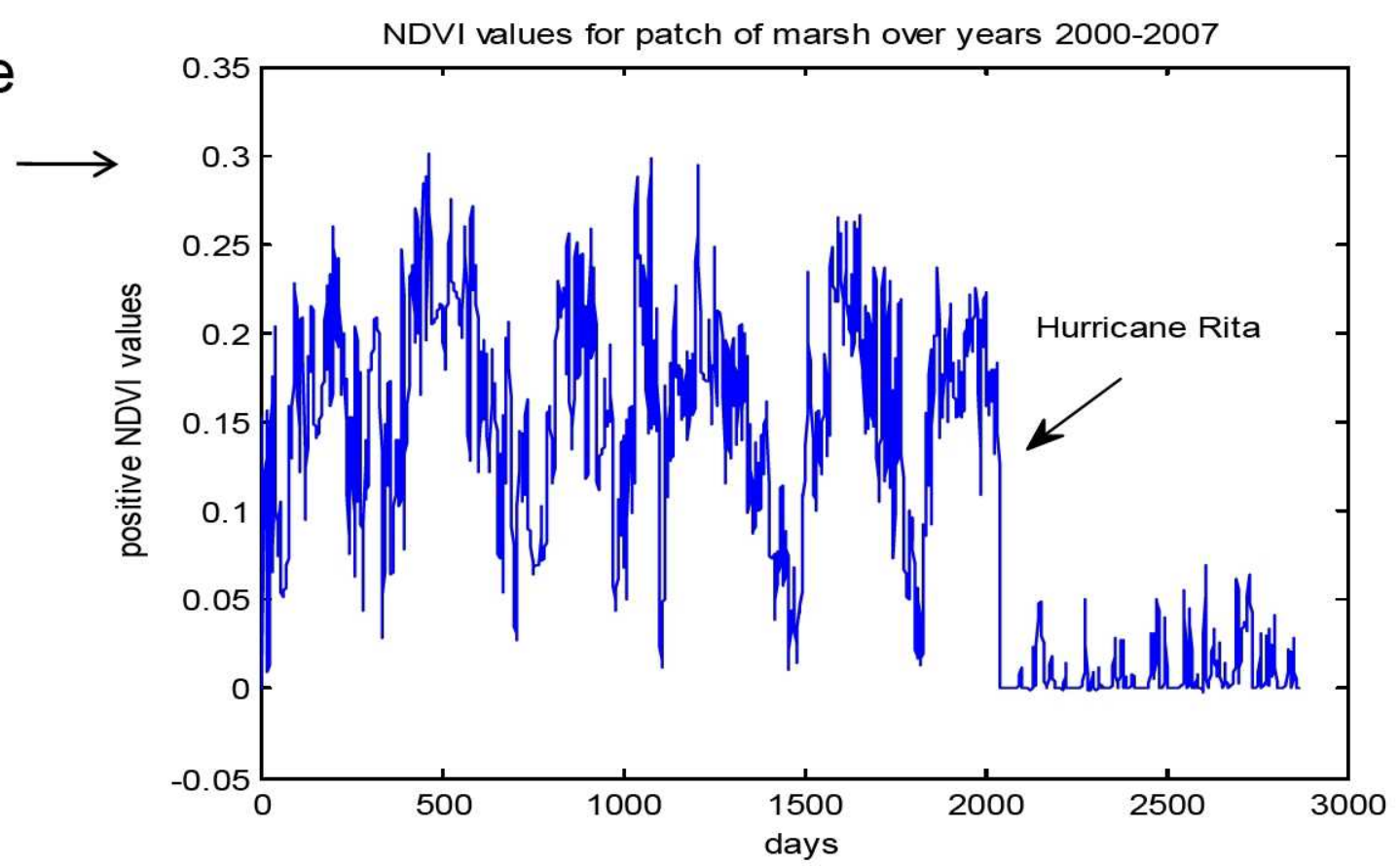




\section{Preliminary Estimates of Annual Percent Inundation from MODIS NDVI}

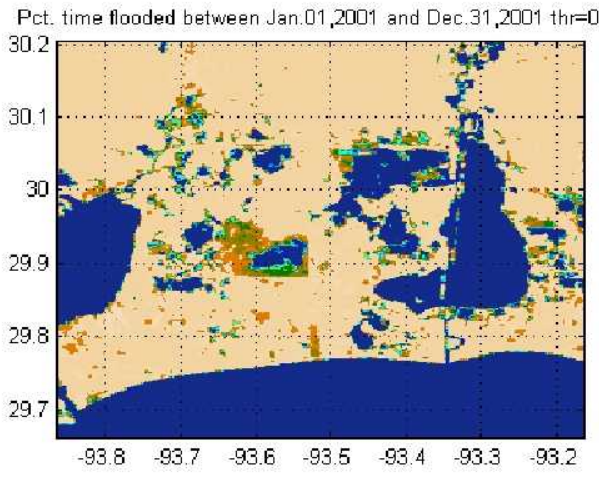

2001

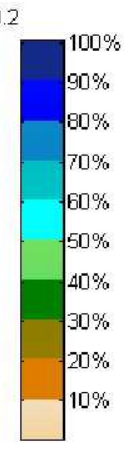

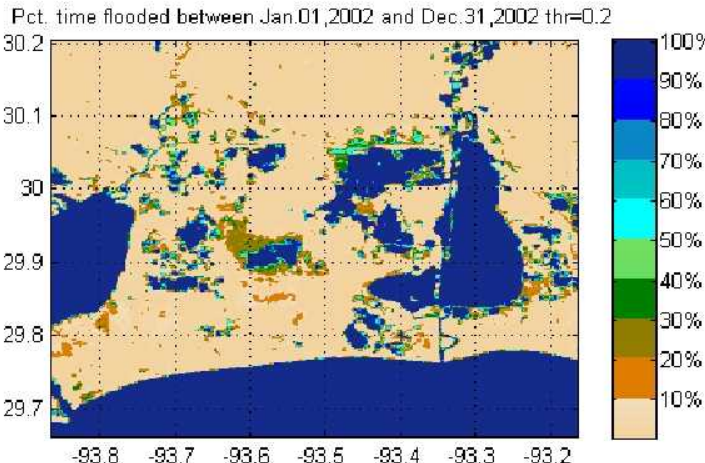

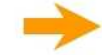

2002

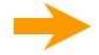

Sabine-Calcasieu Basin Flooding
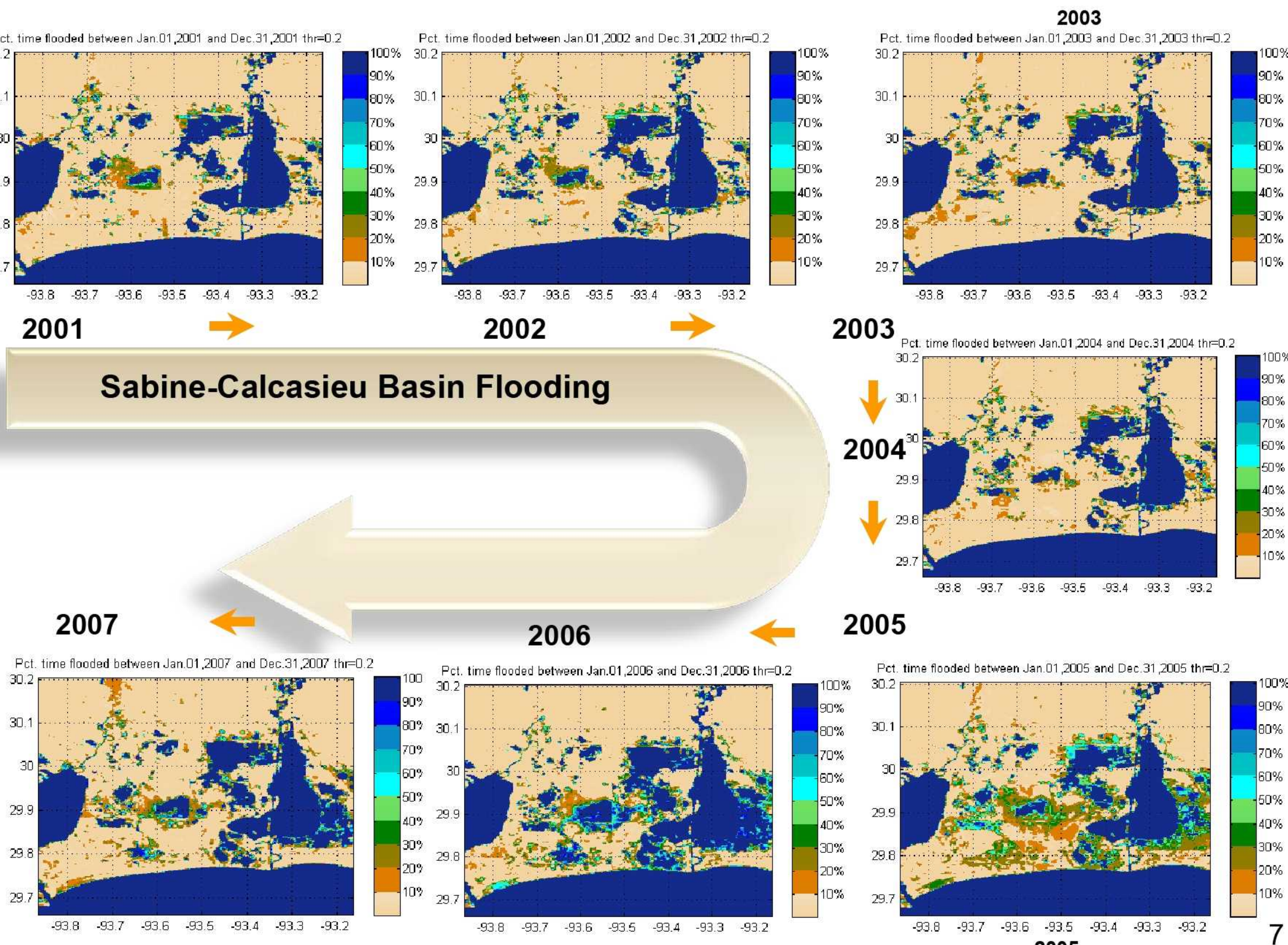

2003

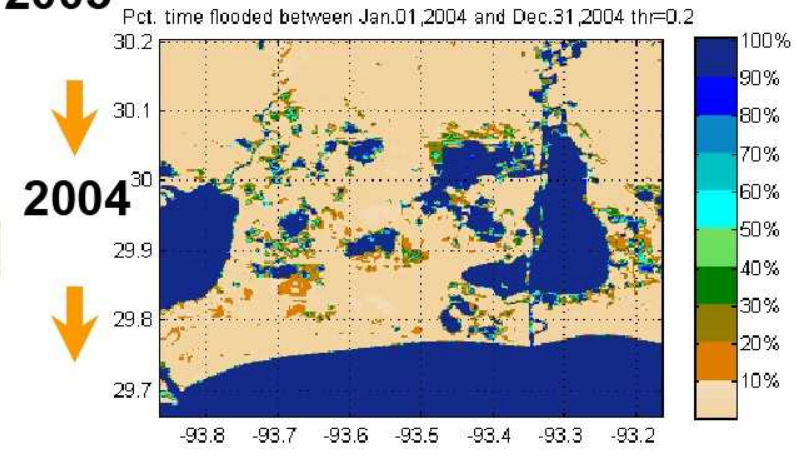

2005

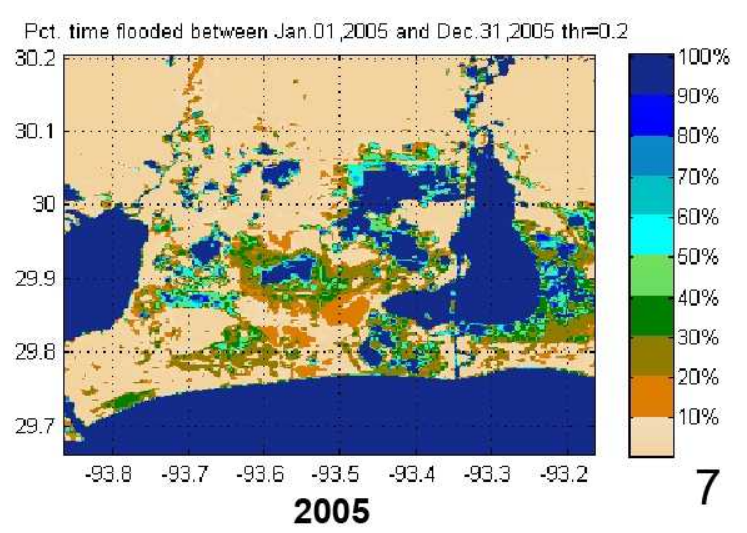



Hurricane Rita

Coastal Restoration Monitoring Station CS20-15R

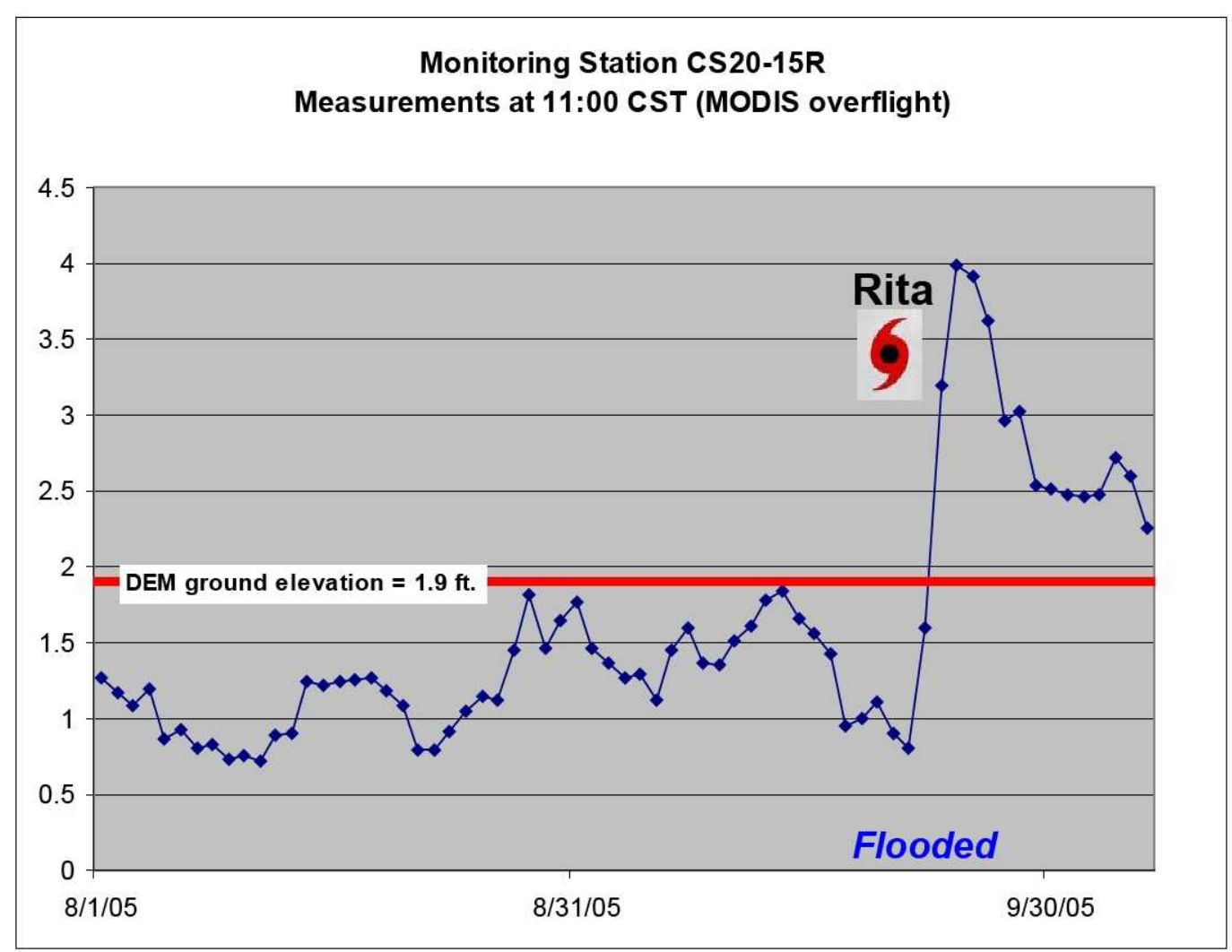




\section{Mud Lake, Sabine-Calcasieu Study Area}

- Flooding determined from comparison of DEM from lidar (NAVD88) and gridded water levels from Coastal Restoration Monitoring Station Field Data (NAVD88) for dates shown below.

- Comparison to Landsat NDWI values for October 31, 2005, shows less flooding in the image. Further work to calibrate water levels to marsh elevation is planned as well as more comparison sites.

Hurricane

Rita

Sept. 24, 2005
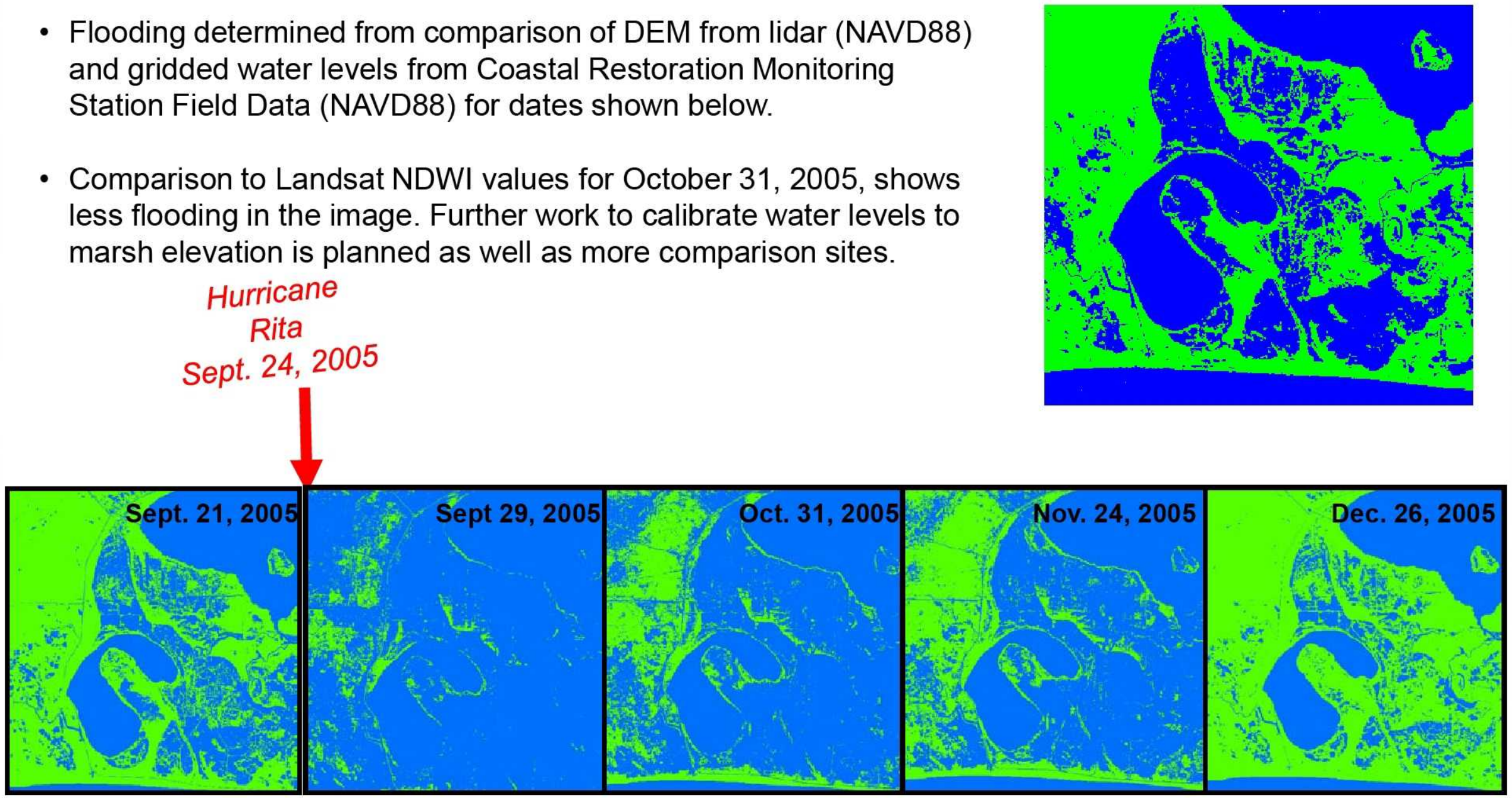


\section{Salinity Distribution 2004-2006}

Fourth Quarter 2004 (October - December)

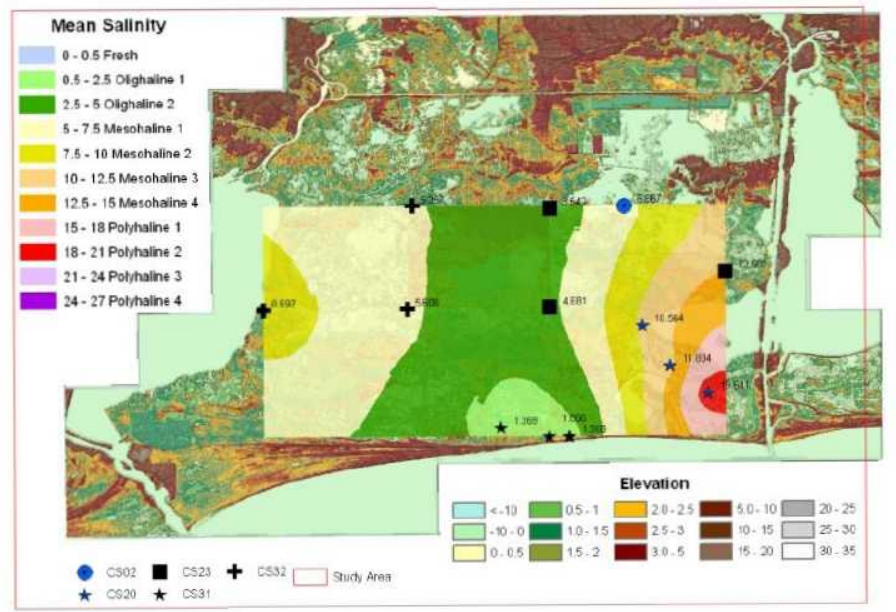

First Quarter 2006 (January - March)

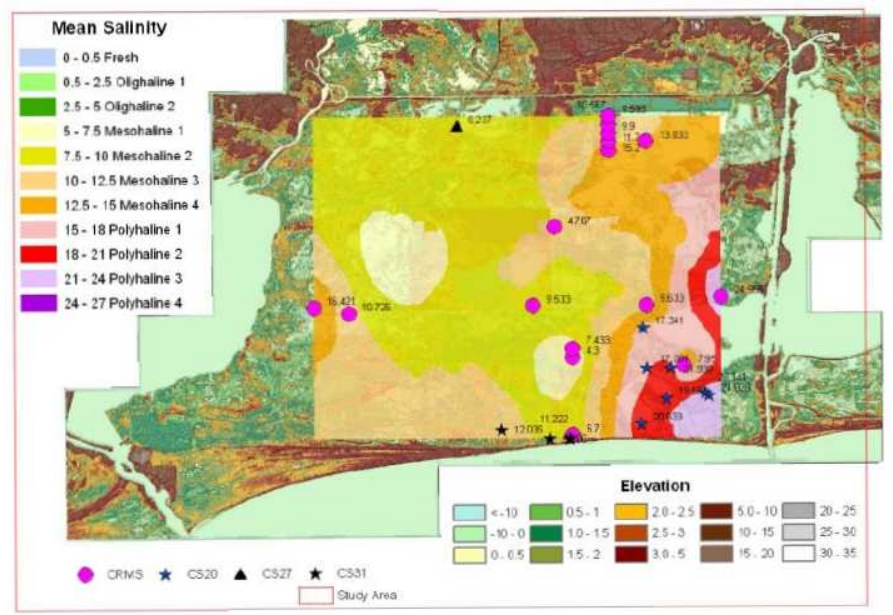

Fourth Quarter 2005 (October - December)

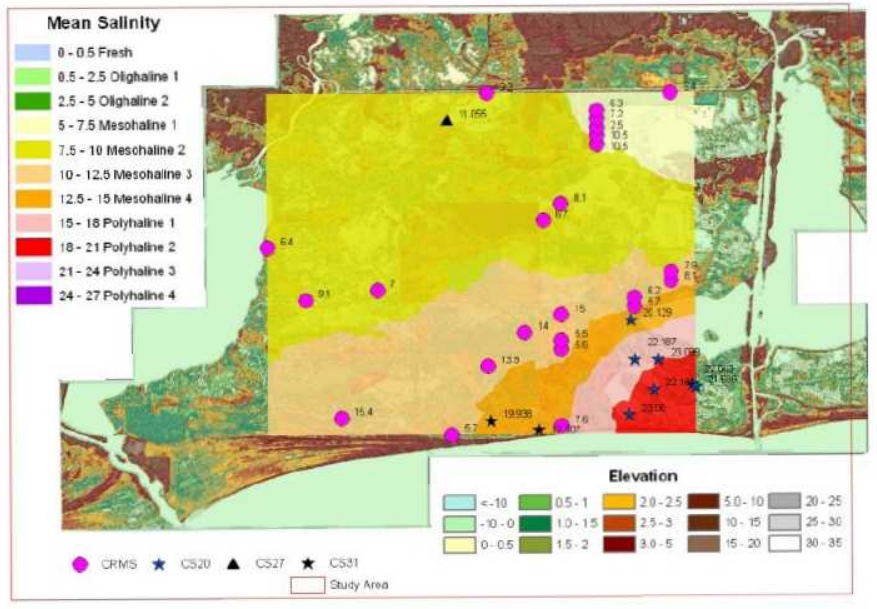

\section{Second Quarter 2006 (April - June)}

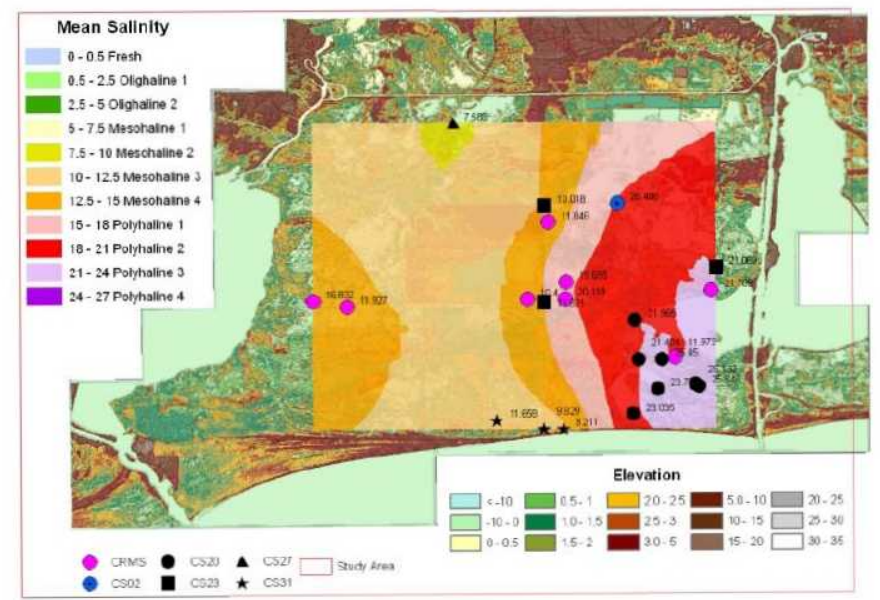




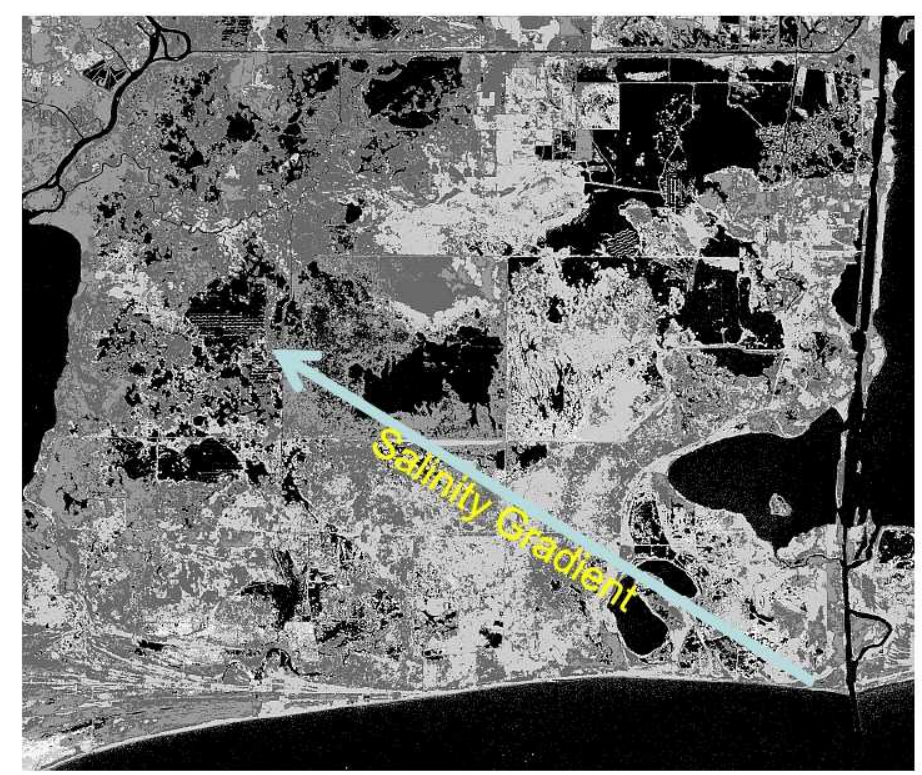

- Porewater salinity maps for Sabine Basin 2005, estimates made from Landsat 7 (10/31/2005) using Neural net, rms $=0.09$

- Salinities range from 0-18 ppt where brighter areas indicate higher salinity 


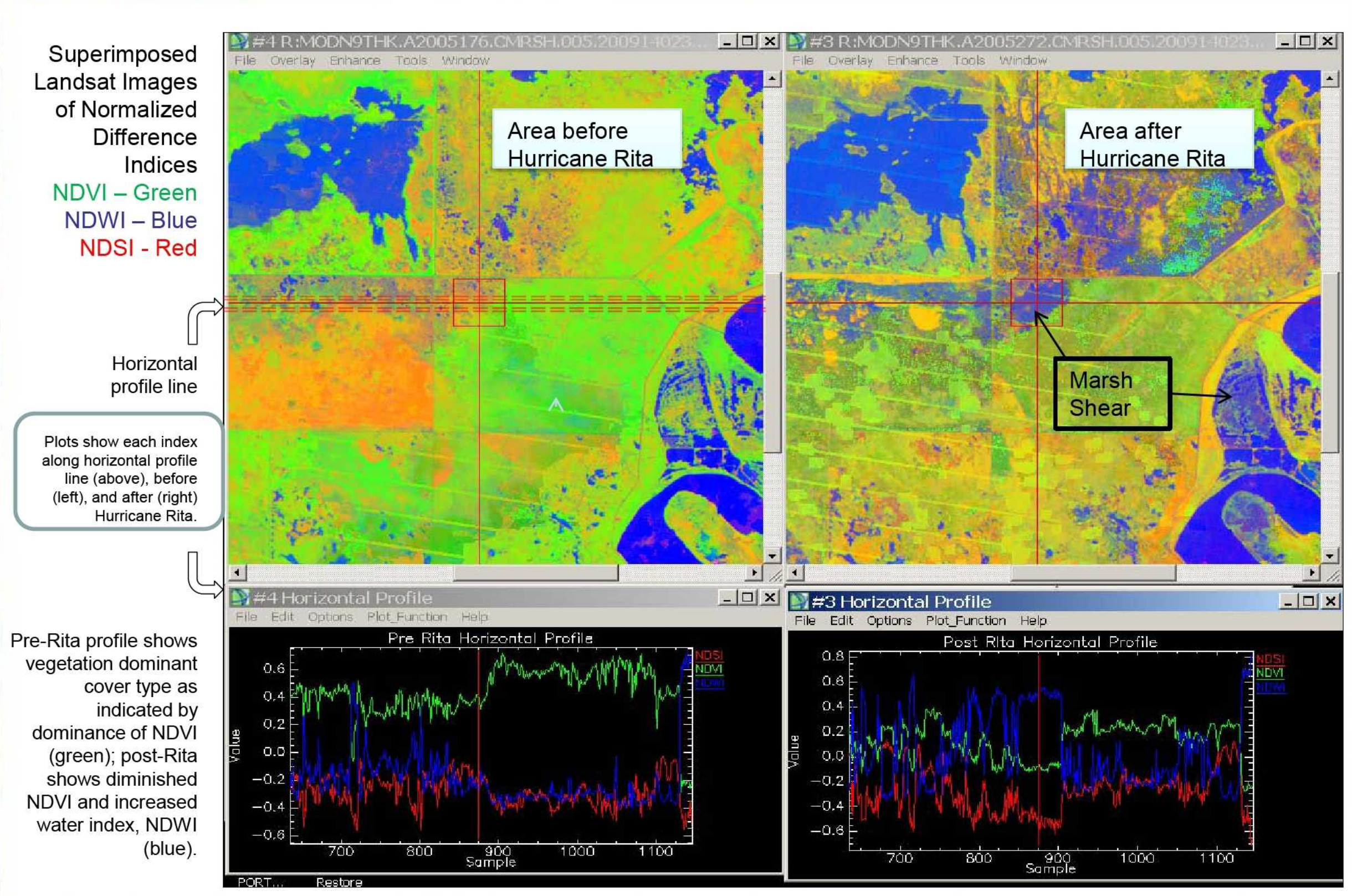



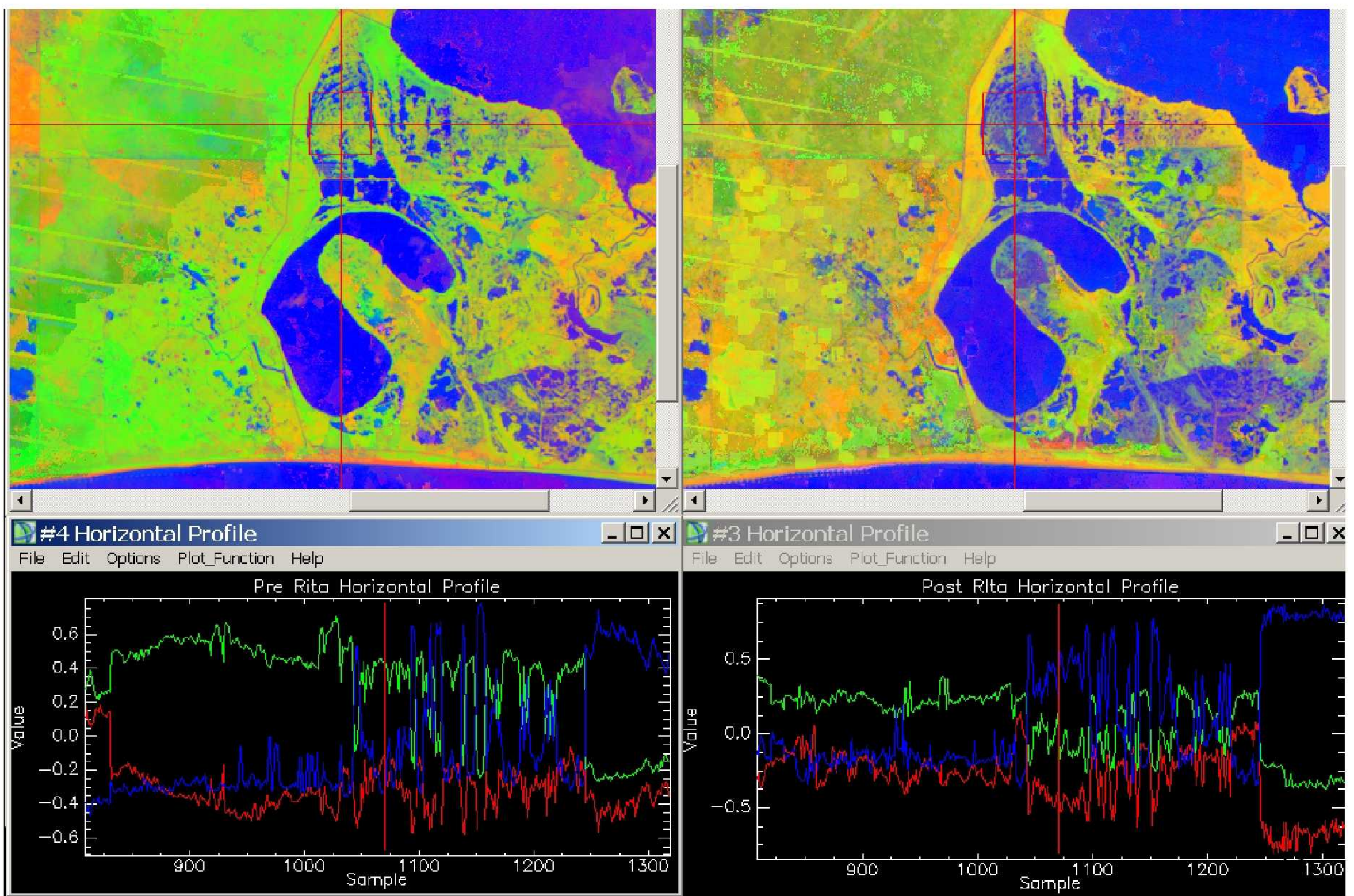
Pre-Rita horizontal profiles show marsh vegetation dominance on horizontal profile (green), while post-Rita shows water (blue) dominating much of the profile.

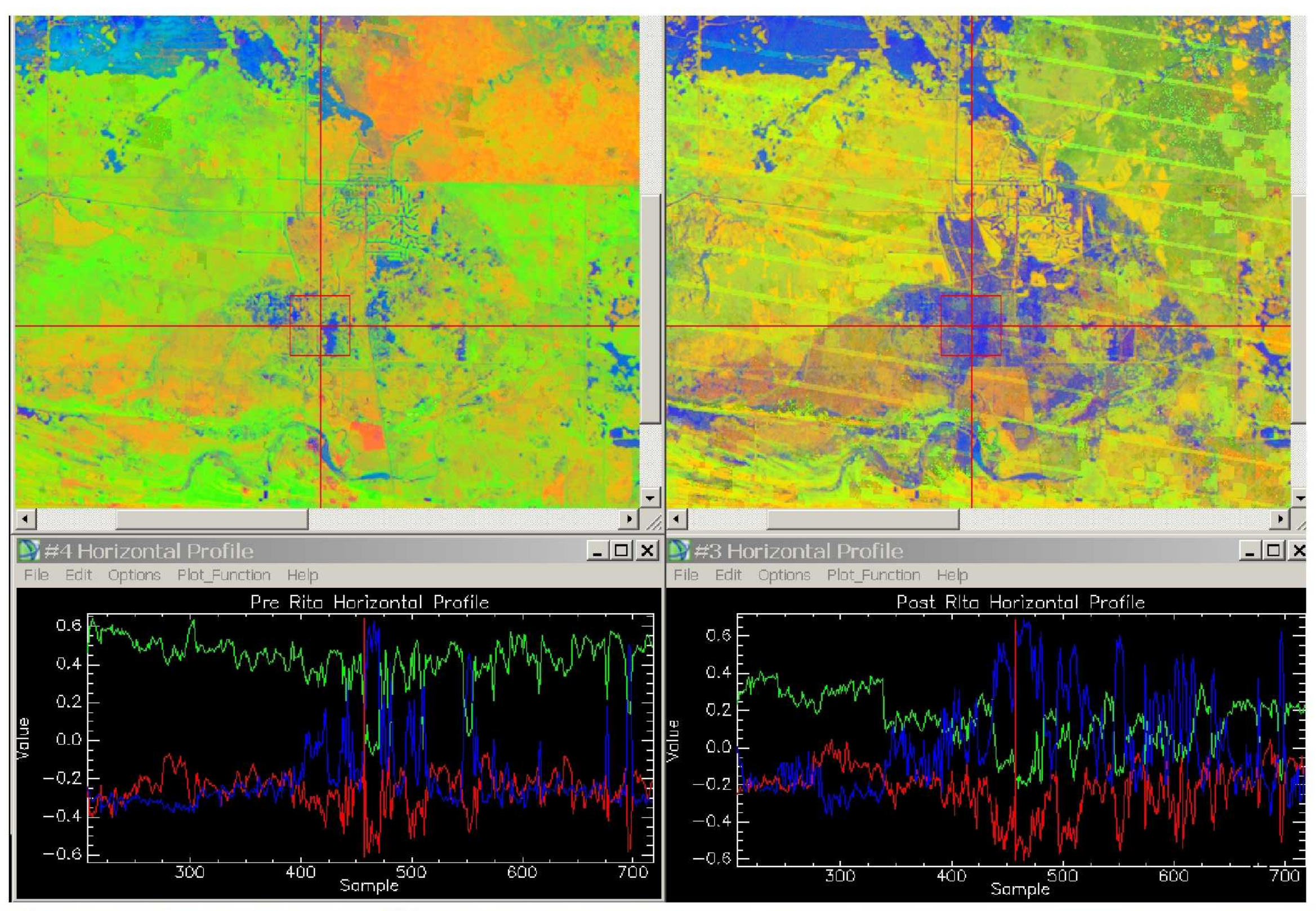




\section{Summary}

- Ongoing work to validate flooding with radar (NWRC/USGS) and enhance persistence estimates through "fusion" of MODIS and Landsat time series (ROSES A.28 Gulf of Mexico).

- Additional work will also investigate relationship between saltwater dielectric constant and radar returns (Radarsat) (ROSES A.28 Gulf of Mexico). 